\title{
CONTROL STRETEGY FOR POWER MANAGEMENT IN GRID CONNECTED MICROGRID WITH RENEWABLE ENERGY SOURCES
}

\author{
Hitesh M. Karkar, Dr. I. N. Trivedi and Hitarth Buch \\ Ph.D. Scholar, Gujarat Technological University, Ahmedabad \\ Assistant Professor, Electrical Engineering Department, L. E. College, Morbi, India. \\ Associate Professor, Electrical Engineering Department, GEC Gandhinagar, India. \\ Assistant Professor, Electrical Engineering Department, G.E.C. Rajkot, India
}

\begin{abstract}
Renewable energy based Distributed Generators (DGs) play a dominant role in electricity production, to reduce global warming. Emerging potential of distributed generation can be realize using microgrid concept. A microgrid consists of cluster of loads and Renewable Energy Sources (RES) that operate as a single controllable system. The microgrid can operated in standalone and grid connected mode. The objective of this paper is to maintained the constant voltage in $A C \& D C$ bus by power management between AC grid, DC sources and load. The droop control algorithm in interlinking bidirectional converter is used to manage the power in microgrid. A microgrid has been modelled and simulated using the Simulink in the MATLAB. The simulation results show that the system can maintain stable operation under the proposed droop control schemes for grid connected mode with variable load condition.
\end{abstract}

Keywords: AC Main Grid, Distributed Generators (DGs), Droop Control, Power Management

Cite this Article: Hitesh M. Karkar, Dr. I. N. Trivedi and Hitarth Buch, Control Stretegy For Power Management in Grid Connected Microgrid With Renewable Energy Sources, International Journal of Electrical Engineering \& Technology, 10(1), 2019, pp. 1-10. http://iaeme.com/Home/issue/IJEET?Volume=10\&Issue $=1$

\section{INTRODUCTION}

Smart grid is the next generation in power system. In this smart grid connection of microgrid is at distribution level, where distribution generation (DG) used [1]. The DG is the small capacity of power generation. There are several types of DG, which is used in microgrid such as power generation from renewable energy like solar photovoltaic (PV), wind, biomass, tides, ocean wave, geothermal etc. These all renewable based DG clean the environment and reduces $\mathrm{CO}_{2}$ emission, so its importance increases today in world. Storage elements (SEs) is also important part of microgrid due to intermittent nature of renewable energy resources and to 
provide smooth power in microgrid [2]. The structure of microgrid system is in form of ac and dc system [3]. It is small grid which is combination of renewable energy sources (RES, storage elements (SEs) and load. Microgrid can reduce transmission and distribution losses, decrease cost, increase efficiency and reliability as compare to conventional grid. Microgrid is a single controllable unit to provide power or need to upper network. It can also improve power quality like voltage and frequency regulation. The microgrid is the basic power source that provide energy in most of rural area [4].

The microgrid system can operate in autonomously islanding (standalone) or grid connected mode [5].

\subsection{Islanded Mode:}

In this mode microgrid can work without grid. It provides power to local load. The role of storage elements is very important in this mode.

\subsection{Grid Connected Mode:}

In Grid connected mode microgrid is connected with main AC grid and interlinking bidirectional converter works flow of power in both directions. AC grid provide the power to microgrid in shortage condition and microgrid dispatched power to grid in surplus condition

The role of power electronics interfaces is most important interfacing device to solve the power management issue [6]. The overview of power management strategy in grid connected mode is shown in fig. 1[7]. In which two method can be used for voltage control and power management in grid connected mode with dispatched and undispatched output power. In first method Interlinking linking converter (ILC) work for control of DC bus voltage. In this mode DGs-SEs on AC bus coordination with DGs-SEs on AC bus is necessary for dispatched power output $[8,9,10]$. In second mode DGs-SEs on DC bus regulate the DC bus voltage control on reference value and ILC and DGs-SEs on AC bus which provide dispatched power. While ILC works on power control mode. In undispatched output power, DGs works on MPPT mode for both AC and DC bus, while ILC on DC link voltage control mode [11,12].

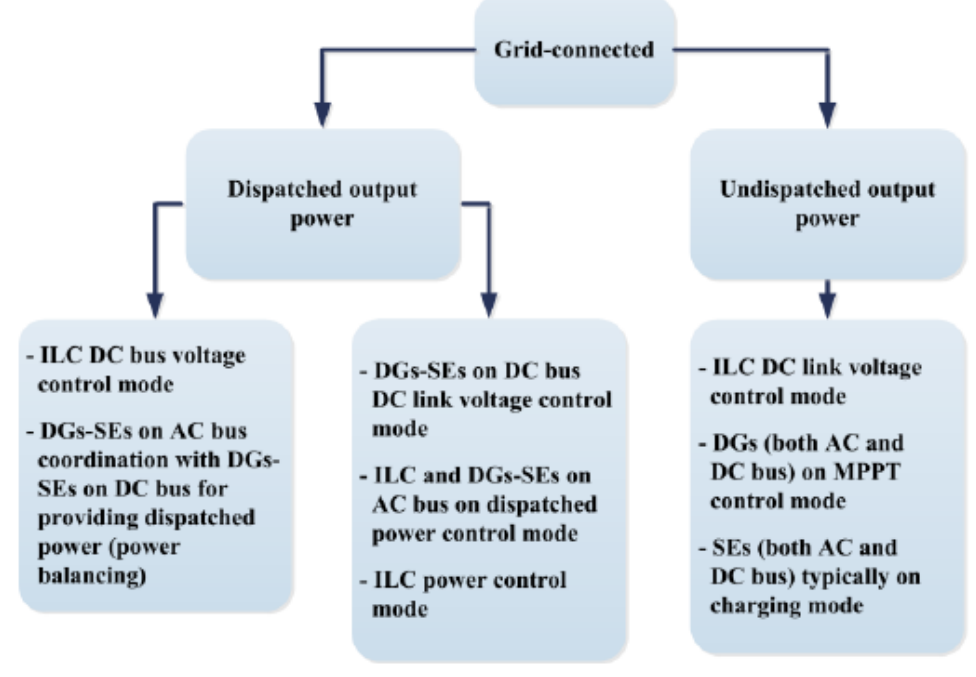

Figure 1 Overview of Power Management Strategies in Grid Connected Mode

Due to use of power converter, microgrid require proper control strategy to import/export power from network, to control of active and reactive power and the voltage and frequency regulation [13]. Microgrid controlled by centrally and autonomously. As per literature survey there are several methods to control and manage the power in grid mode. But in this paper droop 
control method is used for power management due to several its advantage. This method control both active and reactive power in variable load condition. Also, it maintains voltage in both bus and frequency in AC bus.

\section{SYSTEM ARCHITECTURE}

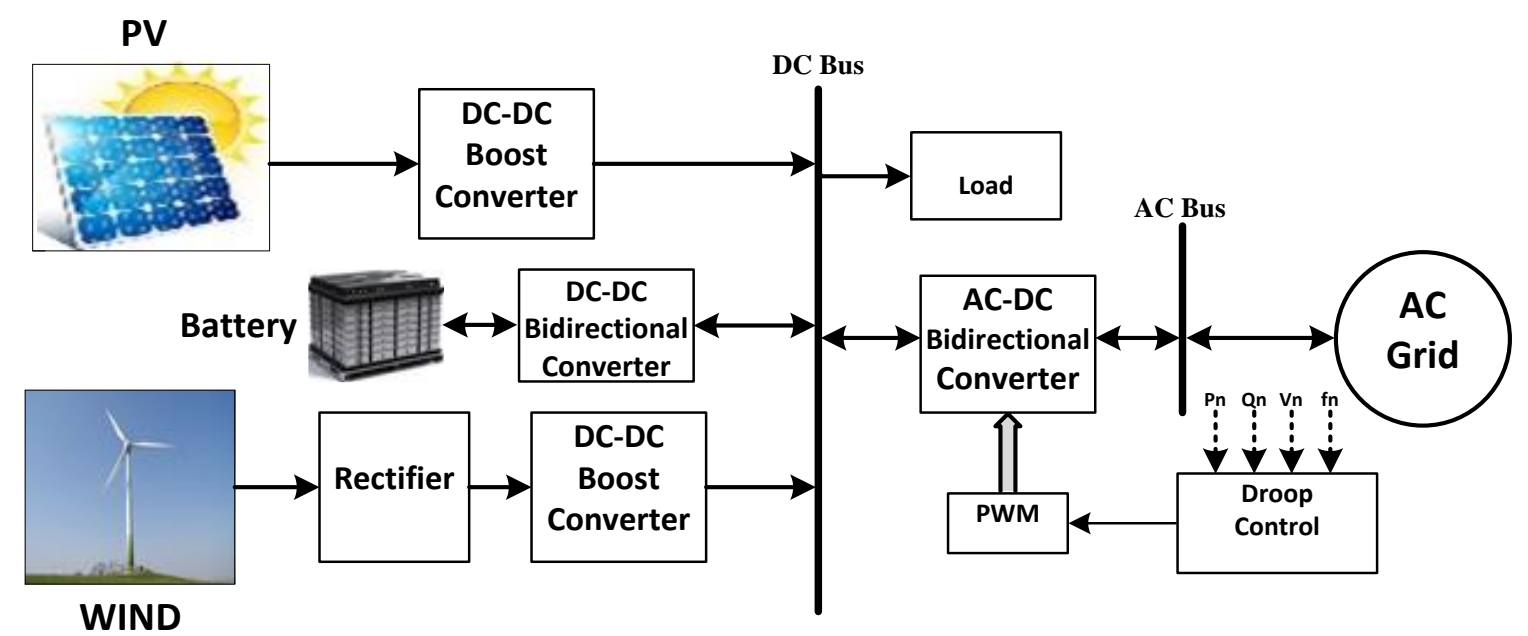

Figure 2 Microgrid Block Diagram

The microgrid system architecture is shown in fig. 2. In which PV array, Wind generator and battery is connected to DC bus of DC microgrid through DC-DC convertor. This DC microgrid is connected to AC main grid through bidirectional DC-AC converter. The power flow in both directions i.e. from DC bus to $\mathrm{AC}$ bus and $\mathrm{AC}$ bus to $\mathrm{DC}$ bus. The main aim is to manage the power between source and load by using droop control of grid interfacing bidirectional interlinking voltage source converter (VSC).

\section{CONTROL OF GRID INTERFACING CONVERTER}

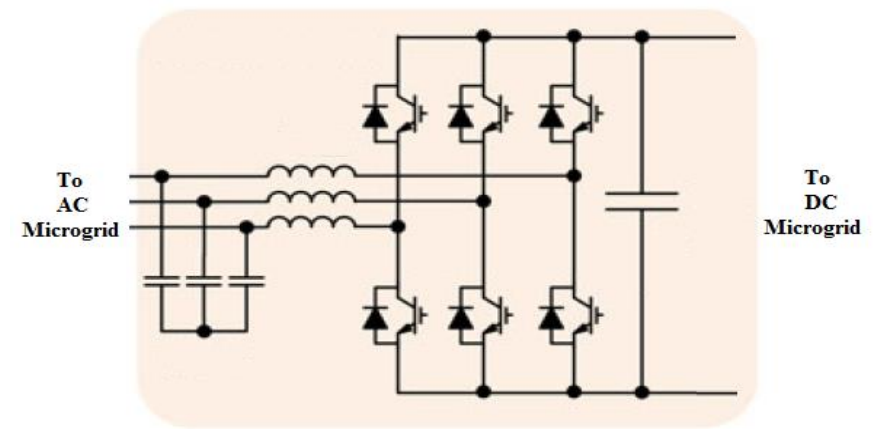

Figure 3 Interlinking Converter

Interlinking converter is considered as shown in fig. 3. It VSC based bidirectional converter. It is used to power flow in both direction between AC and DC bus. To control the bidirectional power flow, droop control strategy is used $[14,15]$.

There are various methods is used to power management in microgrid. Most of methods have a problem of communication. To avoid the communication for increase the reliability of microgrid. Droop control is decentralized based method. There is no need communication in it. As per literature survey there are several advantages of droop control method [16-24]. 


\subsection{Droop Control Scheme for Interlinking Converter}

There are two droop characteristics for control of interlinking converter in grid connected microgrid.

\section{Frequency (f) versus Active Power (P) Droop}

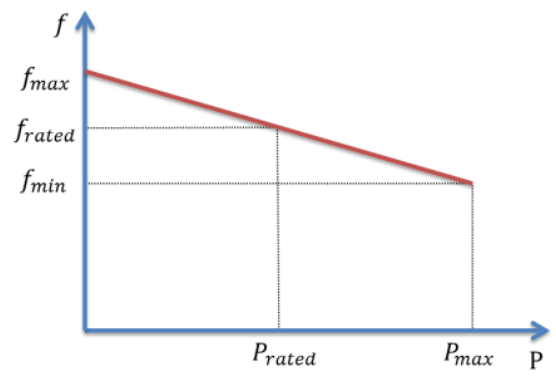

Figure 4 Frequency(f) Vs. active power(P) droop characteristic

Power (P) Vs. frequency (f) droop characteristic is shown in fig. 4. P- $f$ droop control characteristic of one DG unit indicates their power set point when rated load is connected is $P_{\text {rated }}$ and frequency $f_{\text {rated }}$. Droop control will increase the power when decreases the frequency. For example, when a new value of frequency is $f_{\min }$ then the DG will generate maximum power $\mathrm{P}_{\max }$. Based on this droop characteristic active power generation will decide for any frequency deviation. So, in present work based on this frequency deviation amount of power injection from the DC bus to AC bus is calculated. From this power voltage angle is calculated to dispatch controlled power from DC to AC microgrid [25].

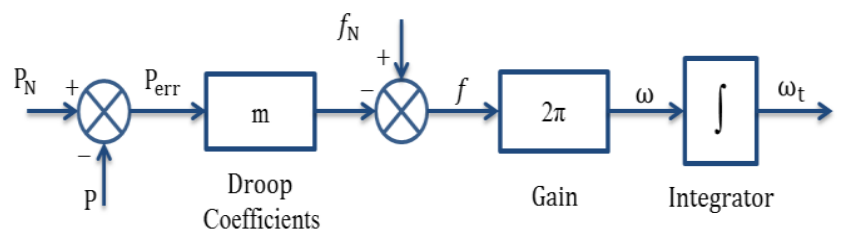

Figure 5 Control diagram of P- $f$ droop Control

The control diagram of P-f droop control is shown in fig. 5. First two input nominal power $\left(\mathrm{P}_{\mathrm{N}}\right)$ and measure power $(\mathrm{P})$ is compared then power error signal is multiplying with $\mathrm{P}-f$ droop coefficient $(\mathrm{m})$. Reference frequency is generating by sensing nominal frequency. Its described in equation (i).

$$
f=f_{\mathrm{N}}-\mathrm{m}\left(\mathrm{P}_{\mathrm{N}}-\mathrm{P}\right)
$$

Where, $f=$ Reference frequency $(\mathrm{Hz})$

$$
\begin{aligned}
& f_{\mathrm{N}}=\text { Nominal frequency }(\mathrm{Hz}) \\
& \mathrm{M}=\mathrm{P}-f \text { droop coefficient }\left(\mathrm{Hz} \mathrm{W}^{-1}\right) \\
& \mathrm{P}_{\mathrm{N}}=\text { Nominal active power }(\mathrm{W}) \\
& \mathrm{P}=\text { Measured active power }(\mathrm{W})
\end{aligned}
$$

The slope of characteristic is constant and it is represented by $\mathrm{P}-f$ droop coefficient (m). It is depending on the values of $\mathrm{P}_{\max }, f_{\min }$ and $f_{\mathrm{MAX}}$ set point. The Droop coefficient $(\mathrm{m})$ is defined from equation (ii).

$$
m=\frac{f_{\mathrm{MAX}}-f_{\mathrm{MIN}}}{\mathrm{P}_{\mathrm{MAX}}}
$$

Where, $\mathrm{m}=\mathrm{P}-f$ droop coefficient $\left(\mathrm{Hz} \mathrm{W}^{-1}\right)$ 
$f_{\mathrm{MAX}}=$ Frequency at minimum power $(\mathrm{Hz})$

$f_{\text {MIN }}=$ Frequency at maximum power $(\mathrm{Hz})$

$\mathrm{P}_{\mathrm{MAX}}=$ Maximum active power $(\mathrm{W})$

\section{Voltage (V) versus Reactive Power (Q) Droop}

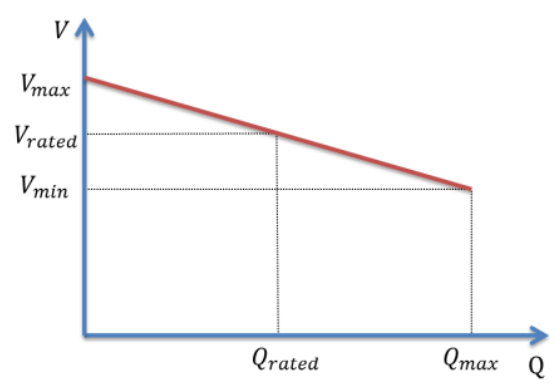

Figure 6 Voltage (V) versus reactive power(Q) droop Characteristic

Reactive power of AC system is depended on voltage. Voltage (V) droop verses reactive power $(\mathrm{Q})$ is shown is fig. 6. When reactive power is increased then voltage of ac system is down. So maximum value of reactive power defined by minimum value of ac system voltage. So, voltage of ac system is maintained by change in reactive power [25].

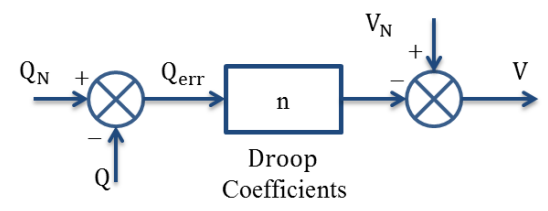

Figure 7 Control diagram of Q-V droop control

The control diagram of $\mathrm{Q}-\mathrm{V}$ droop control is shown in fig. 7. Qerr is generated by compare of nominal reactive power $\left(\mathrm{Q}_{\mathrm{N}}\right)$ and measured reactive power $\mathrm{Q}$. Then $\mathrm{Q}_{\mathrm{err}}$ is multiplying by $\mathrm{Q}-\mathrm{V}$ droop coefficient $\mathrm{n}$. Reference voltage $(\mathrm{V})$ is generated by sensing of nominal voltage (V). Reference voltage (V) is derived from equation (iii).

$\mathrm{V}=$ Reference voltage $(\mathrm{V})$

$$
\mathrm{V}=\mathrm{V}_{\mathrm{N}}-\mathrm{n}\left(\mathrm{Q}_{\mathrm{N}}-\mathrm{Q}\right)
$$

$\mathrm{V}_{\mathrm{N}}=$ Nominal voltage $(\mathrm{V})$

$\mathrm{n}=\mathrm{Q}-\mathrm{V}$ droop coefficient $\left(\mathrm{V} \mathrm{var}^{-1}\right)$

$\mathrm{Q}_{\mathrm{N}}=$ Nominal reactive power (var)

$\mathrm{Q}=$ Measured reactive power (var)

Slope of figure 6 is the Q-V droop coefficient (n). It is depending on the values of $Q_{\max }$, $\mathrm{V}_{\text {min }}$ and $\mathrm{V}_{\mathrm{MAX}}$ set point. The expression Q-V Droop coefficient(n) is shown in equation (iv).

$$
n=\frac{\mathrm{V}_{\mathrm{MAX}}-\mathrm{V}_{\mathrm{MIN}}}{\mathrm{Q}_{\mathrm{MAX}}}
$$

Where, $n=\mathrm{Q}-\mathrm{V}$ droop coefficient $\left(\mathrm{V} \mathrm{VAR}^{-1}\right)$

$\mathrm{V}_{\mathrm{MAX}}=$ Voltage at minimum reactive power $(\mathrm{V})$

$\mathrm{V}_{\mathrm{MIN}}=$ Voltage at maximum reactive power $(\mathrm{V})$

$\mathrm{Q}_{\max }=$ Maximum reactive power (var)

Figure. 8 shows the final implementation of the droop controller. It generates pulse through PWM and control the power flow of interlinking bidirectional converter. 


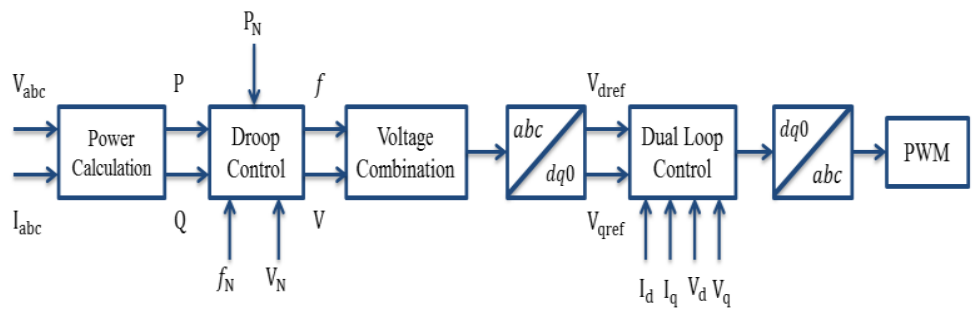

Figure 8 Droop Control Scheme for Interlinking Converter

It includes active and reactive power measurement from the available voltages and currents, P- $f$ and Q-V Droop control, voltage combination, dual loop control, and Pulse Width Modulation (PWM) pulses generation. Droop control regulates the power flow by interlinking converter between $\mathrm{AC}$ and $\mathrm{DC}$ bus.

\subsubsection{Droop Control Subsystem for Interlinking Converter}

Droop control modelled subsystem is shown is fig. 9. In which reference frequency (f) is reference voltage (V) is modelled as per droop equation (i) and (iii) respectively. Reference frequency (f) is calculated from $\mathrm{P}-f$ droop control and it generate sin and cos reference. Reference voltage $(\mathrm{V})$ is calculated form $\mathrm{Q}-\mathrm{V}$ droop control. Then $\mathrm{V}_{\mathrm{dr}}$ and $\mathrm{V}_{\mathrm{qr}}$ is generated from abc to dq0 transformation.

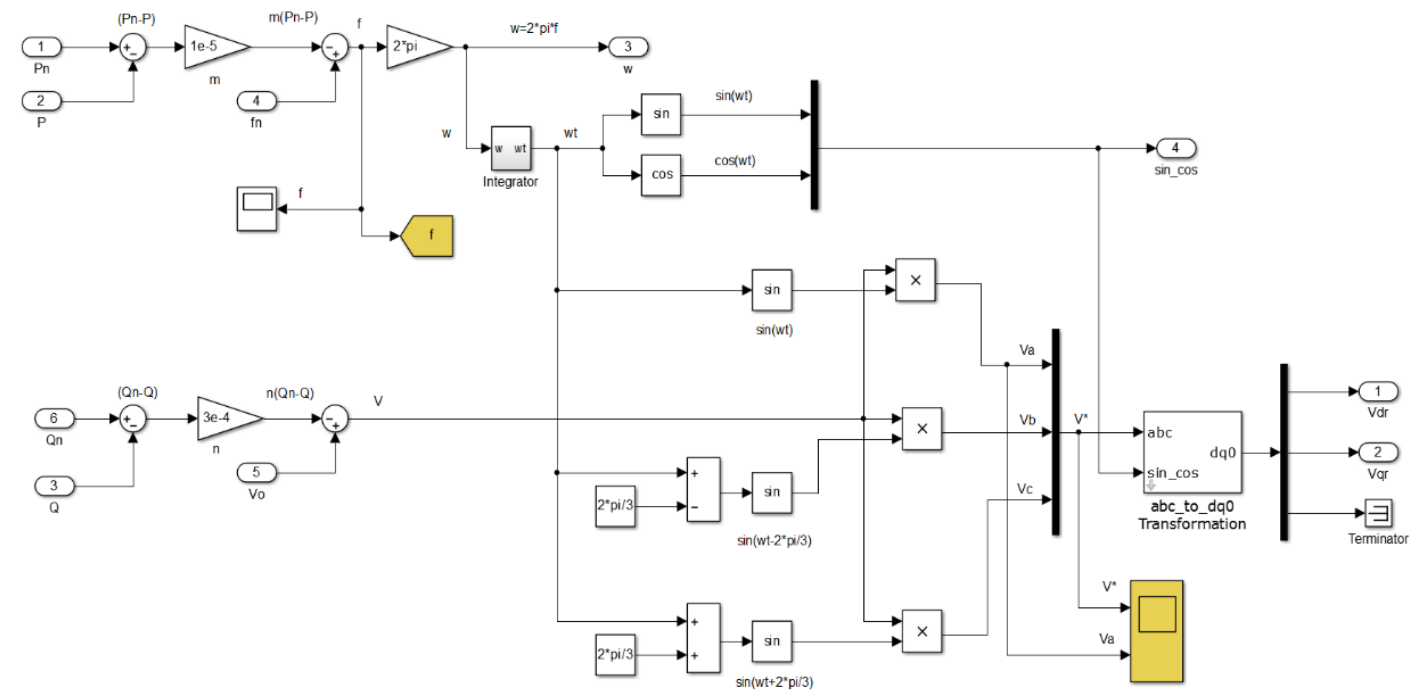

Figure 9 Droop Control Scheme Subsystem

\subsubsection{PWM Subsystem for Interlinking Converter}

To generate PWM gate pulses, dual closed loop subsystem is modelled as shown in fig.10. This subsystem is designed as per equation ( $\mathrm{v}$ ) and (vi). $\mathrm{V}_{\mathrm{dr}}$ and $\mathrm{V}_{\mathrm{qr}}$ is compare with $\mathrm{V}_{\mathrm{d}}$ and $\mathrm{V}_{\mathrm{q}}$ respectively. In this subsystem voltage is maintained by outer loop and power flow controlled by current inner loop.

$$
C \frac{d v_{d r}}{d t}=\left(v_{d r}-v_{d}\right)+\omega C V_{q r}
$$

$C \frac{d v_{q r}}{d t}=\left(v_{q r}-v_{q}\right)-\omega C V_{d r}$ 


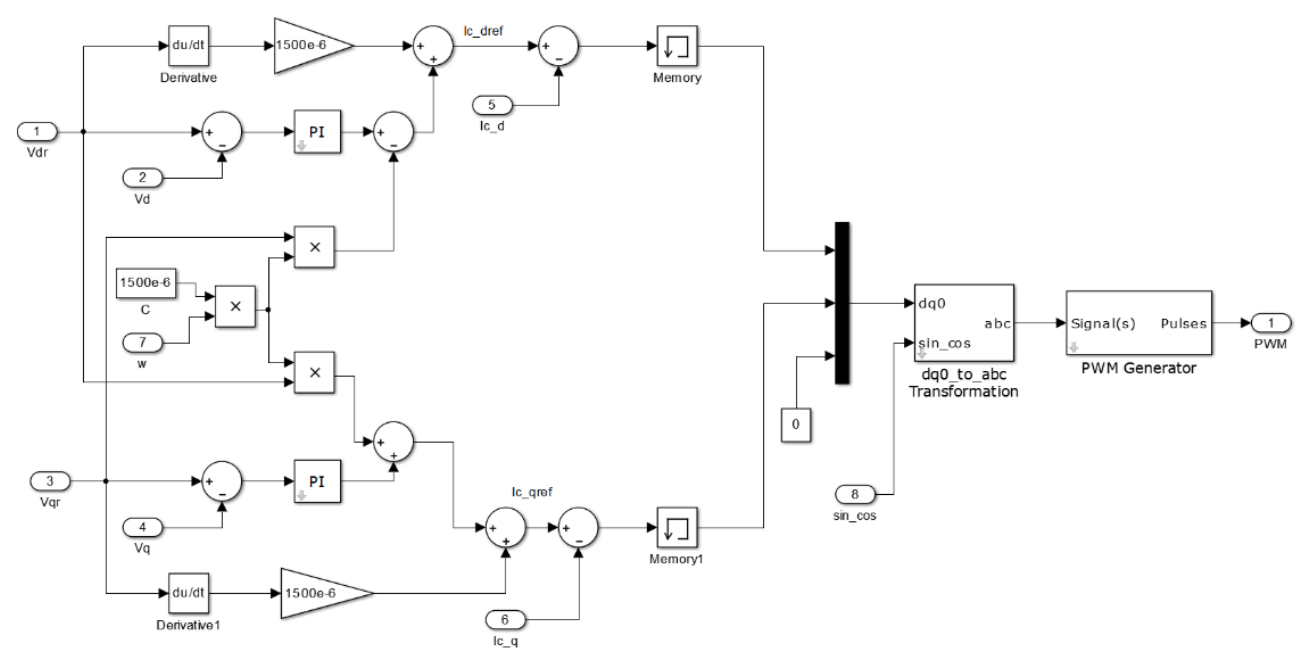

Figure 10 PWM Subsystem

\section{SIMULATION RESULT}

The MATLAB Simulink model results for the four different operation of micro-grid is obtained which is given in fig. 11 to 16 . In fig. 11, as per load variation power transfer from grid. Due to droop control strategy equal power sharing by DG and grid. Battery is zero due to fully charged. When load power and generation power is same, so there is no transfer power between AC Grid and DC Grid. As per fig. 12 when load power is higher than generated power, so power transfer from AC Grid to DC Grid and generating power is higher than grid power, so power transfer from DC Grid to AC Grid. Active power and reactive power of grid is shown in fig. 13. As per fig. 14 current of ac grid is changed between $0.5 \mathrm{~s}$ to $2.5 \mathrm{~s}$ due to power transfer between AC grid and DC grid. As per fig. 15, AC bus voltage of microgrid is maintained constant during load variation due to droop control technique. DC bus voltage of microgrid is also maintained constant as per fig. 16.
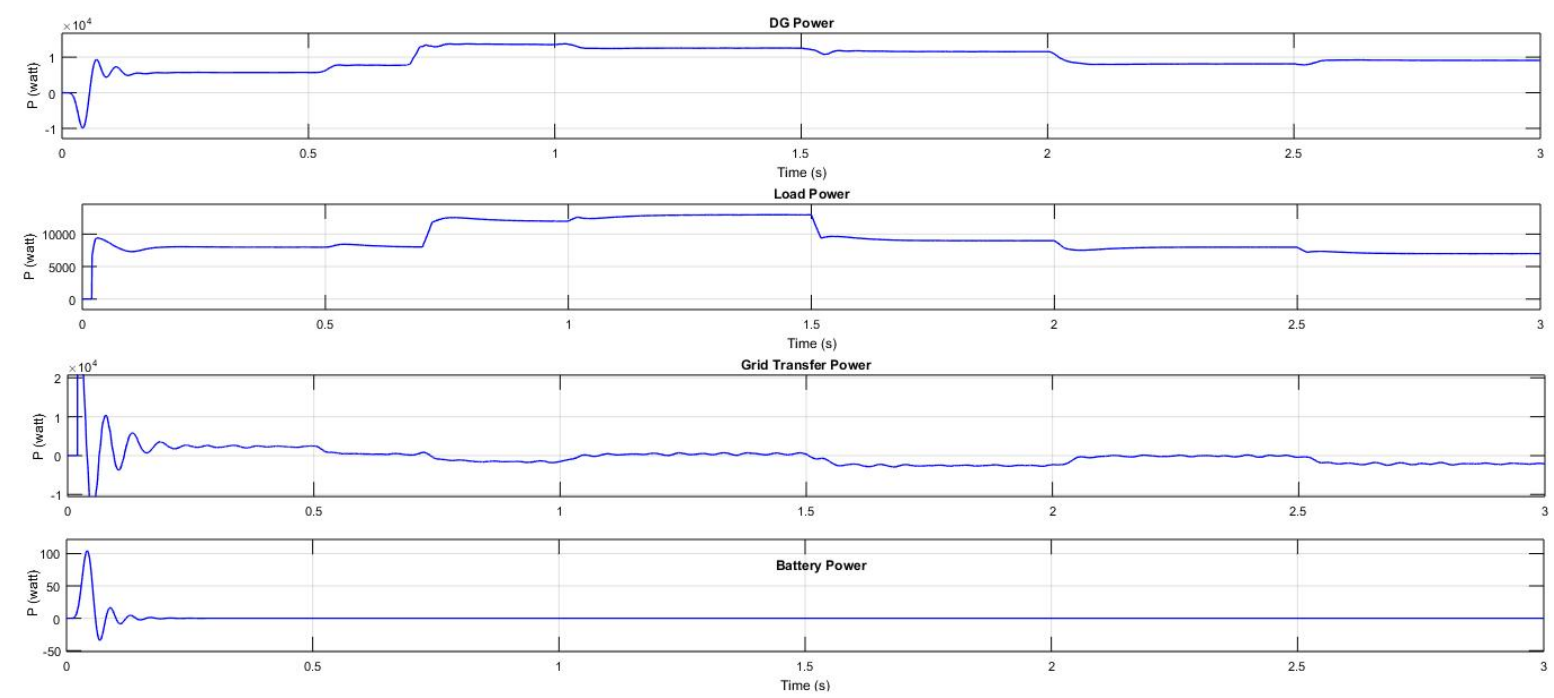

Figure 11 Power Waveform of Microgrid 
Control Stretegy For Power Management in Grid Connected Microgrid With Renewable Energy Sources
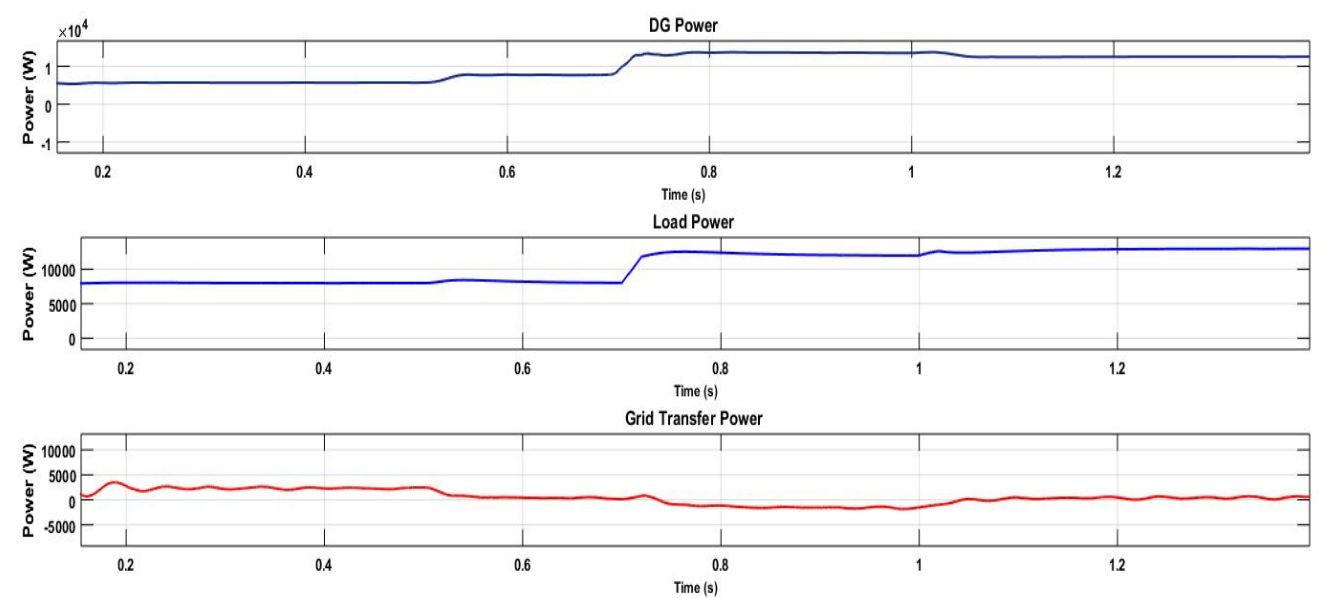

Figure 12 Grid Power Transfer
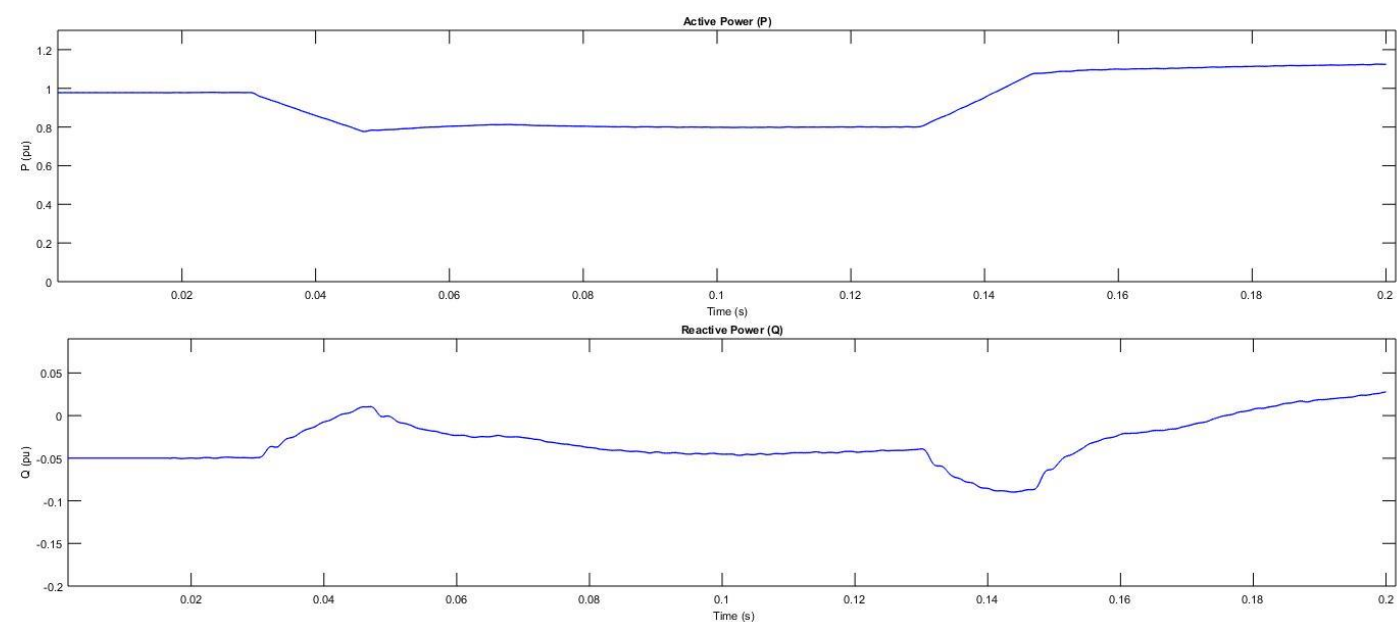

Figure 13 Active and Reactive Power of AC Grid

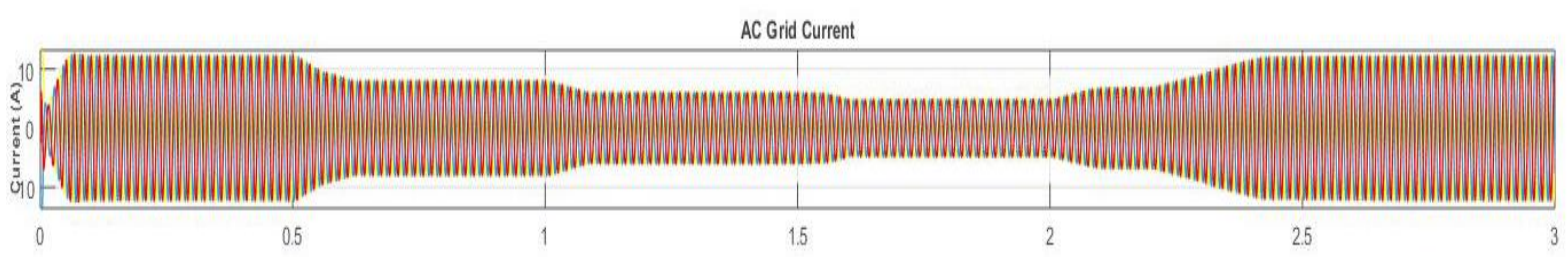

Figure 14 Current of AC Grid

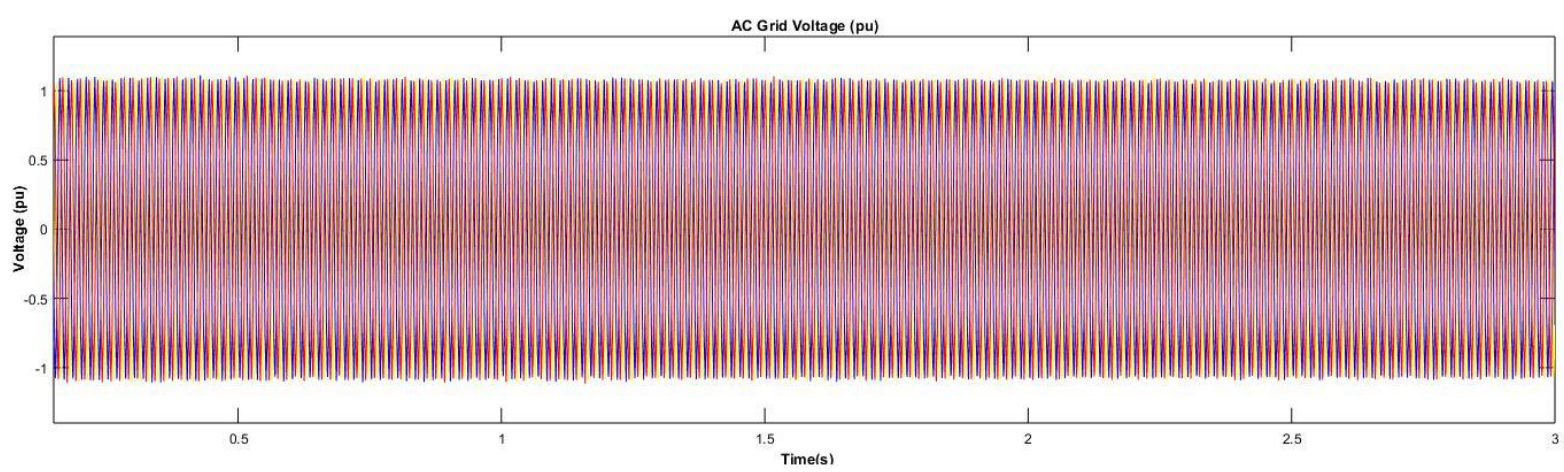

Figure 15 Voltage of AC Grid 


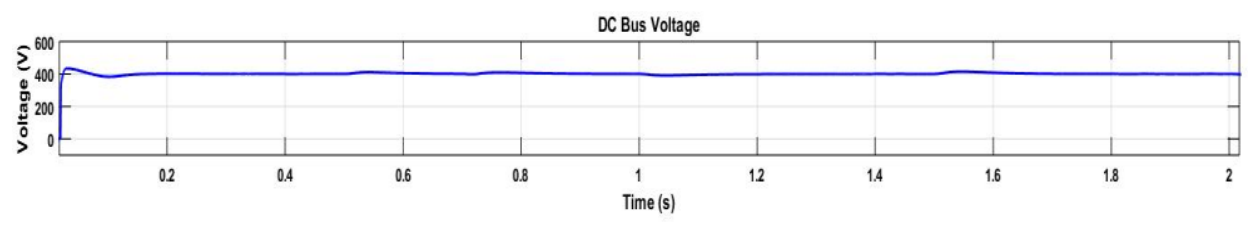

Figure 16 DC Bus Voltage

\section{CONCLUSION}

This paper presents a droop control strategy of bidirectional interlinking converter in renewable sources dominated grid connected microgrid. MATLAB simulation-based result is obtained for variable source and load condition. The models are developed for the all converters to maintain stable AC and DC bus voltage under various loads and source. Droop control strategy is operated interlinking bidirectional converter such that manage the power between DG, Grid and load in microgrid. It is also ensuring the smoothness of power flow and the stability of Grid. The simulation results are verified that implemented control strategy maintained constant AC \& DC voltage and smooth power transfer between AC grid and DC bus in stable operation under static and dynamic load condition.

\section{REFERENCE}

[1] G. Pepermansa, J. Driesenb, D. Haeseldonckxc, R. Belmansc, W. D’haeseleer, "Distributed Generation: definition, benefits and issues", ELSEVIER Energy Policy 33, pp. 787-798, 2005.

[2] D. J. Hammerstrom, “AC Versus DC Distribution Systems Did We Get It Right?” in IEEE Power Engineering Society General Meeting, pp. 1-5, 2007.

[3] R. H. Lasseter, P. Paigi, "Microgrid: A conceptual solution," in PESC'04 Aachen, Germany, IEEE, pp. 4285-4290, 2004.

[4] Nikos Hatziargyriou, "Microgrids: Architectures and Control", Wiley-IEEE Press, ISBN: 978-1-118-72068-4, pp. 1-340, December 2013.

[5] T. Zhou, and B. Francois, "Energy Management and Power Control of a Hybrid Active Wind Generator for Distributed Power Generation and Grid Integration," IEEE Trans. Industrial Electronics, Vol.58, No.1, pp.95-104, Jan. 2011.

[6] W. Tang, and R.H. Lasseter, "An LVDC industrial power distribution system without central control unit," in Proc. IEEE PESC, June 2000, pp.979-984.

[7] Farzam Nejabatkhah, Yun Wei Li, "Overview of Power Management Strategies of Hybrid AC/DC Microgrid”, IEEE Transactions on Power Electronics, December 2014.

[8] P. Ch. Loh, D. Li, Y. K. Chai, and F. Blaabjerg, "Autonomous Operation of Hybrid Microgrid With AC and DC Subgrids", IEEE Trans. Power Electron. vol. 28, no. 5, pp. 2214-2223, May. 2013.

[9] P. Ch. Loh, D. Li, Y. K. Chai, and F. Blaabjerg, "Autonomous Control of Interlinking Converter with Energy Storage in Hybrid AC-DC Microgrid”, IEEE Trans. Ind. App., vol. 49, no. 3, pp. 1374-1383, May 2013.

[10] H. Louie, and K. Strunz, "Superconducting Magnetic Energy Storage (SMES) for Energy Cache Control in Modular Distributed Hydrogen-Electric Energy Systems", IEEE Trans. Applied Superconductivity, vol. 17, no. 2, pp. 2361-2364, Jun. 2007.

[11] X. Liu, P. Wang, and P. Ch. Loh, "A Hybrid AC/DC Microgrid and Its Coordination Control,” IEEE Trans. Smart Grid, vol. 2, no. 2, pp. 278-286, Jul. 2011. 
[12] Zh. Jiang, X, Yu, "Hybrid DC- and AC-Linked Microgrids: Towards Integration of Distributed Energy Resources," IEEE Energy 2030 Conf., pp.1-8, Nov. 2008.

[13] Jackson John Justo a, Francis Mwasilu, Ju Lee, Jin-WooJung, "AC-microgrids versus DCmicrogrids with distributed energy resources: A review", Renewable and Sustainable Energy Reviews, 24 (2013) 387-405

[14] Poh Chiang Loh, Ding Li, Yi Kang Chai, Blaabjerg F., "Autonomous Control of Interlinking Converter with Energy Storage in Hybrid AC-DC Microgrid," Industry Applications, IEEE Transactions on, vol.49, no.3, pp. 1374-1382, March 2013.

[15] Poh Chiang Loh, Ding Li, Yi Kang Chai, and Frede Blaabjerg, "Autonomous Operation of Hybrid Microgrid with AC and DC Subgrids", IEEE Transactions on Power Electronics, pp. 2214 - 2223, vol. 28, no. 5, May 2013.

[16] R. H. Lasseter, "Microgrids," in Proc. IEEE Power Eng. Soc. Winter Meeting, New York, NY, USA, 2002, pp. 305-308.

[17] R. H. Lasseter and P. Paigi, "Microgrid: A conceptual solution," in Proc. IEEE Power Electron. Spec. Conf., Aachen, Germany, 2004, pp. 4285-4290.

[18] P. Piagi and R. H. Lasseter, "Autonomous control of microgrids," in Proc. Power Eng. Soc. Gen. Meeting, Montreal, QC, Canada, 2006, pp. 8-15.

[19] M. C. Chandorkar, D. M. Divan, and R. Adapa, "Control of parallel connected inverters in standalone AC supply systems," IEEE Trans. Ind. Appl., vol. 29, no. 1, pp. 136-143, Jan. 1993.

[20] M. C. Chandrokar, D. M. Divan, and B. Blaabjerg, "Control of distributed UPS systems," in Proc. 25th Annu. IEEE Power Electron. Spec. Conf., Taipei, Taiwan, 1994, pp. 197-204.

[21] Y. B. Byun, T. G. Koo, and K. Y. Joe, "Parallel operation of three-phase UPS inverters by wireless load sharing control," in Proc. Tele commu. Energy Conf., Phoenix, AZ, USA, 2000, pp. 526-532.

[22] J. M. Guerrero, L. G. de Vicuna, and J. Matas, "Output impedance design of parallelconnected UPS inverters with wireless load-sharing control," IEEE Trans. Ind. Electron., vol. 52, no. 4, pp. 1126-1135, Aug. 2005.

[23] J. M. Guerrero, J. C. Vasquez, and J. Matas, "Control strategy for flexible microgrid based on parallel line-interactive UPS systems," IEEE Trans. Ind. Electron., vol. 56, no. 3, pp. 726-736, Mar. 2009.

[24] J. Hu, J. Zhu, D. G. Dorrell, and J. M. Guerrero, "Virtual flux droop method-A new control strategy of inverters in microgrids," IEEE Trans. Power Electron., vol. 29, no. 9, pp. 47044711, Sep. 2014.

[25] M. Ashabani, Y. Mohamed, M. Mirsalim, and M. Aghashabani, "Multivariable droop control of synchronous current converters in weak grids/microgrids with decoupled dq-axes currents," IEEE Trans. Smart Grid, to be published.

[26] L. Y. Lu and C. C. Chu, "Consensus-based droop control synthesis for multiple DICs in isolated micro-grids," IEEE Trans. Power Syst., to be published.

[27] M. Goyal, A. Ghosh, F. Zare, Power sharing control with frequency droop in a hybrid microgrid, in Power and Energy Society General Meeting (PES), IEEE, 2013, pp. 1-5 